\title{
A NARRATIVA CONFESSIONAL EM BOYHOOD, DE J. M. COETZEE: DA TEORIA À PRÁTICA
}

\author{
João Pedro Wizniewsky Amaral \\ Lawrence Flores Pereira ${ }^{2}$
}

Resumo: Boyhood (1997) é o primeiro volume da trilogia autobiográfica Scenes from Provincial Life, do escritor sul-africano J. M. Coetzee. A narrativa de Boyhood tem características peculiares para um romance autobiográfico, como o narrador em terceira pessoa e o uso do tempo presente. A partir de uma discussão acerca de narrativas confessionais tradicionais na literatura, baseada em estudos teóricos de Coetzee, este artigo tem como objetivo propor uma breve análise das características da narrativa nessa obra para verificar como a confissão se faz presente em Boyhood. Assim, esse estudo também é uma apresentação de alguns elementos constituintes de sua seletividade literária na construção de suas autobiografias ficcionais.

Palavras-chave: narrativa confessional; escrita de si; J. M. Coetzee.

Abstract: Boyhood (1997) is the first book of Coetzee's autobiographical trilogy, Scenes from Provincial Life. The narrative in Boyhood has a peculiar and original characteristic if we consider more typical and traditional autobiographical writings: two of its curious literary strategies are Coetzee's strategic use of third-person narrator and the Present Tense. Departing from one of Coetzee's theoretical studies on confession and literature, we analyze some main narrative constituents of Coetzee's novel as the development of non-religious confessional technics that Coetzee manipulated with a view to evade the typical confessional short-cuts the author formerly studied and criticized in authors as J. J. Rousseau and Dostoyevsky.

Keywords: confessional narrative; selfwriting; J. M. Coetzee.

\footnotetext{
${ }^{1}$ Possui graduação em Letras - Inglês pela Universidade Federal de Santa Maria (2013) e graduação em Comunicação Social pela Universidade Federal de Santa Maria (2010). Atualmente é mestrando em Letras pela UFSM Mestrando em Estudos Literários do Programa de Pós-Graduação em Letras da UFSM. E-mail: shuaum@gmail.com

${ }^{2}$ Professor adjunto da Universidade Federal de Santa Maria. Possui período de pós-doutorado na Universidade de Massachusetts, no Massachusetts Center for Interdisciplinary Renaissance Studies. Tem experiência na área de Letras, com ênfase em Línguas Estrangeiras Modernas, Teoria da Literatura e Estudos da Tradução, atuando principalmente nos seguintes temas: história literária, filosofia, tradução poética, teoria da literatura e estética. Em tradução poética realizou traduções de poesia moderna (T. S. Eliot, Baudelaire) e de textos dramáticos (Sófocles e Shakespeare).E-mail: lawflores@gmail.com
} 


\section{Introdução}

No final da década de noventa, com a publicação de Boyhood: Scenes from Provincial Life (1997), J. M. Coetzee iniciava a composição daquilo que viria a ser chamado de sua trilogia autobiográfica. Ela foi continuada por Youth (2003), que trata da juventude de Coetzee, e Summertime (2009), romance multifocal com várias "testemunhas" que falam do "falecido" autor. Muito se falou do modo peculiar com que Coetzee combina (sua) autobiografia com ficção, e gostaríamos aqui, a propósito, de mostrar alguns elementos constituintes de sua seletividade literária na constituição de suas autobiografias ficcionais.

Boyhood narra o crescimento pessoal do menino John Coetzee, homônimo do autor, em uma segregada África do Sul, a partir do ponto de vista ingênuo e impreciso do protagonista. Os fatos narrados e as descobertas feitas por John são apresentados por meio de suas impressões extremamente sensoriais do mundo em que vive. As histórias acontecem predominantemente em ambientes típicos do universo infantil, como em sua própria casa, na casa de familiares e na escola.

A narrativa do romance utiliza técnicas que remetem a recursos cinematográficos, como a narração de eventos na forma de flashes. Além do mais, Coetzee adota o narrador em terceira pessoa e o uso do tempo presente (Present Simple) em sua narrativa, diferenciando-se de autobiografias tradicionais. John Coetzee, o protagonista fictício de Boyhood, passa por experiências em que suas impressões são ainda incipientes para compreender a totalidade dos acontecimentos e também, em certa medida, os problemas políticos e sociais que uma criança normalmente é incapaz de entender.

No tocante a questões de gênero literário, Boyhood apresenta peculiaridades estilísticas quando comparado a outras autobiografias. Lejeune (1989) define autobiografia como "a retrospective prose narrative written by a real person concerning his own existence, where the focus is his individual life" (LEJEUNE, 1989, p. 4). O autor acrescenta que, a partir dessa definição, o gênero autobiográfico apresenta quatro características fundamentais: a narrativa em prosa; a temática da vida particular; a equivalência do autor com o

Revista Eletrônica Literatura e Autoritarismo: Narrativa Testemunhal e Relações Históricas - ISSN 1679-849X |101| http://cascavel.ufsm.br/revistas/ojs-2.2.2/index.php/LA/index 
narrador e, consequentemente com o protagonista; e o ponto de vista retrospectivo da narrativa.

No entanto, Boyhood traz apenas as duas primeiras características listadas por Lejeune. No romance de Coetzee, o narrador em terceira pessoa permite certa desvinculação entre em o narrador (e o autor) e o seu protagonista, o que deve afetar a própria seleção de temas, cenas e conteúdos narrados em geral. Esse procedimento também tende a afastar o efeito de memorização pessoal retrospectiva, aliado ao uso do tempo presente que definitivamente faz com que o ato narrativo se deixe entrelaçar menos como os traços formulaicos típicos das narrativas memoriais. Boyhood é, assim, uma autobiografia híbrida que se afasta substancialmente do conceito de autobiografia de Lejeune por utilizar de uma narrativa em terceira pessoa e pela ausência da voz narrativa memorialista e documental. Mesmo assim, Lejeune indica que pode haver flexibilidade no gênero autobiográfico, como algumas narrativas que são feitas em terceira pessoa para obter o efeito de um afastamento entre autor e o protagonista da narração (LEJEUNE, 1990, p. 42). Dois exemplos de autobiografias escritas em terceira pessoa são as memórias de Cesar e parte da obra Autobiography of Youth, de Daniel Guérin. Sobre o gênero autobiográfico em terceira pessoa, Smith e Watson (2010) especulam, a partir das autobiografias de Coetzee e de Henry James, que "the effect of deploying the third-person pronoun is to disrupt the expectation of first-person intimacy, to create a sense of self-alienation through objectification, and to open a gap between the narrating 'l' and an implicit narrating 'he' or 'she"' (SMITH; WATSON, 2010, p. 74).

Muitos leitores leigos podem acreditar erroneamente que a autobiografia deve ser baseada na confirmação dos fatos históricos de vida de alguém (EAKIN, 2014, p.1). No entanto, para Eakin (2014), há a produção de ficção na autobiografia, por ela ser elaborada a partir do uso criativo da linguagem. 0 autor complementa que a autobiografia é um gênero que implementa uma negociação entre a criação ficcional e os "fatos" biográficos. Tal premissa corrobora a afirmação de Atwell (2015), segundo a qual "Coetzee's autobiography is the ficcion itself" (ATWELL, 2015, p.6)

Estudos recentes afirmam ainda que o termo autobiografia pode ser bastante genérico, e sugerem sua substituição por life writing ou life narrative |102| 
(SMITH; WATSON, 2010, p.4). Entretanto, David Attridge (2004) sugere que Boyhood seja classificado como uma "outrobiografia", pois, com o distanciamento do sujeito observado, o seu autor não poderia ser confundido com o seu "personagem": em outros termos, o Coetzee escritor não se confunde com o menino Coetzee de Boyhood. Sobre o uso da terceira pessoa na voz narrativa e o uso do tempo presente, Attridge (2004) afirma:

\begin{abstract}
O uso da terceira pessoa implicitamente desassocia a voz do narrador da consciência narrada, nos dizendo que essa é outra pessoa, dizendo-nos que estamos lendo, para usar um termo de Coetzee, uma outrobiografia, e não uma autobiografia. Ao mesmo tempo, o uso do tempo presente tanto reforça a urgência dos eventos narrados quanto nega qualquer retrospecção ao texto, qualquer lugar a partir do qual o escritor possa refletir e expressar arrependimentos (ou aprovação) sobre os atos e atitudes descritos (ATTRIDGE, 2004, p. 143).
\end{abstract}

Coetzee especula sobre dinamismo do gênero autobiográfico, em seu ensaio sobre William Faulkner, de 2003. Usando as palavras de Parini, biógrafo de Faulkner, Coetzee diz que escrever sobre alguém é muito menos historiográfico que parece e mais parecido com a escrita de um romance (COETZEE, 2010, p. 202). Como é patente em suas entrevistas, bem como em seus textos teóricos e literários sobre narrativas de si, o autor sul-africano demonstra interesse pela verdade da narrativa.

Sua atenção por essa verdade da narrativa (seja autobiográfica ou não) interessantemente $\mathrm{O}$ afasta de quase todas as formas do relativismo pósmoderno. De acordo com Pereira e Rosenfield (2015), sua obstinação ficcionista "desafia precisamente esse tipo de generalidade, afirmando a relevância de uma experiência singular e verdadeira" (PEREIRA; ROSENFIELD, 2015, p. 11). Na ficção de Coetzee (em Boyhood não é diferente) há a preocupação com a representação sincera de uma narrativa verdadeira e da genuína experiência de vida, ainda que essa experiência não tenha existido tal como aparece na narrativa.

O parágrafo que abre Boyhood ilustra esse modo de narrar:

They live on a housing estate outside the town of Worcester, between the railway line and the National Road. The streets of

\footnotetext{
${ }^{3}$ Esse termo foi usado pelo próprio Coetzee, em entrevista para David Atwell (1992)

Revista Eletrônica Literatura e Autoritarismo: Narrativa Testemunhal e Relações Históricas - ISSN 1679-849X |103| http://cascavel.ufsm.br/revistas/ojs-2.2.2/index.php/LA/index
} 
the estate have tree-names but no trees yet. Their address is No. 12 Poplar Avenue. All the houses on the estate are new and identical. They are set in large plots of red clay earth where nothing grows, separated by wire fences. In each back yard stands a small block consisting of a room and a lavatory. Though they have no servant, they refer to these as 'the servant's room' and 'the servant's lavatory.' They use the servant's room to store things in: newspapers, empty bottles, a broken chair, an old coir mattress (COETZEE, 1997, p. 1).

A descrição da residência dos Coetzees é simples e objetiva. Ao longo do trecho, a voz narrativa traz imagens do mundo pobre do menino, a partir de natureza aparentemente insignificante, como a casa da família, a argila vermelha que não é fértil, jornais, garrafas vazias e cadeiras quebradas. A presença da natureza é tão distante que a casa em que vivem está no meio de duas construções urbanas: entre uma ferrovia e uma rodovia. Além do mais, a rua onde os Coetzees moram possui nome de árvore, embora não existam árvores de fato na rua.

No discurso, não há comentários de caráter social. A voz narrativa não presta serviços de sociólogo. Porém, ao se fazer objetivo e evitar intrusivamente juízos sobre o espaço físico, o narrador deixa a cargo do leitor o trabalho de nomear, conectar e interligar o contexto. Assim, no trecho acima, relativamente despojado e seco, há ironia, por exemplo, na menção ao quarto de empregada (servant's room). Esse microcosmos é uma predefinição para essa criança das segregações do mundo social da África do Sul. As funções e divisões sociais são transpostas para o espaço físico, que é perceptível para uma criança. A simbologia do quarto de empregada como um espaço segregado segue a percepção simples e banal de um jovem. Em nenhum momento, o narrador atribui ou sinaliza o significado que esses espaços possam possuir.

Lejeune (1989, p. 29) diz que o gênero autobiográfico é um gênero "contractual", definido por relações pactuais entre leitor e autor que têm por centro um certo acordo sobre a verdade do narrado, uma verdade que deve estar de algum modo relacionada ao autor. Em autobiografias tradicionais, esse pacto autobiográfico se dá pela confiança na voz do narrador. Contudo, o pacto autobiográfico firmado em Boyhood é de outra ordem: o leitor é exigido a completar as situações, as palavras e as sugestões do narrador. 


\section{Confissões: a teoria e a prática de J. M. Coetzee}

Diferente da simples autobiografia, a narrativa confessional consiste em uma autoinvestigação peculiar que se centra em fatos que podem ser dolorosos, sentidos como vergonhosos ou culpáveis. Antes de escrever Boyhood, obra em que estão presentes vestígios confessionais, Coetzee mostrou interesse sobre os problemas referentes a confissões em seu artigo Confession and Double Thoughts: Tolstoy, Rousseau, Dostoevski (1985). Há elos entre os temas escritos por Coetzee em seus ensaios teóricos e seus romances "autoreferenciais". Attridge (2010) afirma que Coetzee, como crítico literário, "seems to have read everything relevant to his subject, often obscure Works in author's oeuvre; he writes with easy familiarity of the historical, cultural and political background" (ATTRIDGE, 2010, p. xiii).

$\mathrm{O}$ artigo de Coetzee sobre confissões inicia com a análise de uma conhecida passagem de As Confissões (1985), de Santo Agostinho, na qual Agostinho lembra sua participação no roubo de pêssegos de um vizinho. Com a narração, ele pretende discutir a origem do sentimento que o levou àquela ação. $O$ ato é importante para Agostinho porque se trata de conhecer a origem do mal, e por isso o centro das atenções do homem confessional é justamente a infância: o momento em que se poderia imaginar como anterior a toda influência malévola.

Partindo do exemplo da narrativa confessional religiosa de Santo Agostinho, Coetzee (1985) pondera que a confissão:

is one component in a sequence of transgression, confession, penitence, and absolution. Absolution means the end of the episode, the closing of the chapter. (...) Absolution in this sense is therefore the indispensable goal of all confession, sacramental or secular. In contrast, transgression is not a fundamental component (COETZEE, 1985, p. 194).

Coetzee analisa a absolvição como elemento significativo para a narrativa confessional religiosa, pois está relacionada à obtenção da graça divina. Esse elemento final do processo é entendido como uma espécie de libertação da opressão da memória (COETZEE, 1985, p. 194). Portanto, n'As Confissões de Santo Agostinho há algo confessado que transcende a Revista Eletrônica Literatura e Autoritarismo: Narrativa Testemunhal e Relações Históricas - ISSN 1679-849X | $\mathbf{1 0 5 |}$ http://cascavel.ufsm.br/revistas/ojs-2.2.2/index.php/LA/index 
trivialidade da história do roubo da fruta: uma verdade sobre ele que ele mesmo, Agostinho, desconhece. Coetzee chama esse princípio de twofold confession, posto que há uma confissão racional e consciente (um confessor relata algo que o fere e causa-Ihe desconforto) e uma confissão em que acontece a revelação hipotética do eu para alguém (leitor), um outro que está ou não presente. Então, a escrita de si, como uma narrativa confessional, é uma forma de buscar autoconhecimento.

Em contraste com esse primeiro exemplo de narrativa confessional em Santo Agostinho, Coetzee evoca Rousseau (1964) para caracterizar uma narrativa confessional laica. Em sua obra Confissões, Jean-Jacques afirma, desde o início da obra, ao modo de uma declaração de princípio, que se compromete em narrar tudo sobre sua história pessoal, sem deixar escapar nada, incluindo na narração até mesmo os episódios inconfessáveis de sua vida.

Vou empreender uma coisa sem exemplo, e cuja realização não será imitada. Quero mostrar aos meus semelhantes um homem em toda a verdade da natureza, e esse homem serei eu. Eu só. Sinto o meu coração, e conheço os homens. Não sou feito como nenhum dos que tenho visto; ouso crer não ser feito como nenhum dos que existem. Se não valho mais, sou pelo menos diferente. Se a natureza fez bem ou mal, ao quebrar o molde em que me vazou, é o que só poderá ser julgado depois de me haverem lido (ROUSSEAU, 1964, p. 15).

Trata-se aqui de um legítimo pacto autobiográfico com o qual Rousseau pretende se tornar um herói confessativo, afirmando que suas confissões serão transparentes e totalmente vinculadas à verdade. A narrativa confessional de Rousseau é um modo de confissão laico porque ela não parte do pecado e não segue a sequência final do processo confessional religioso, que é a busca para conseguir o perdão e, talvez, a graça divina. Coetzee (1985, p. 205) considera que ambos os casos, a narrativa confessional religiosa e a laica, podem ser questionáveis, deliberando ou não algum conhecimento sobre o eu.

Embora com vieses diferentes, o que há de similar na narrativa em Rousseau e em Santo Agostinho é o motivo de escrever sobre si mesmo. De acordo com Coetzee, o motivo de uma autonarrativa confessional é "to seek to 
communicate or express the essencial nature, the truth, of the self' (COETZEE, 1985, p. 194).

O interesse de Coetzee pela confissão religiosa e, sobretudo, pela confissão laica está na sua diferença essencial e qualitativa com outras formas de narrativas (auto)biográficas. Se as narrativas autobiográficas não necessariamente tratam de um estudo da consciência de um sujeito; a confissão, ao contrário, obrigatoriamente terá que incluir aquelas memórias de acontecimentos cuja evocação é dolorosa. No entanto, a confissão muitas vezes pode ficar refém de uma narrativa conjugada na primeira pessoa. A contínua referência a si nas narrações confessionais mantém a excessiva proximidade entre o narrador e o sujeito biografado (autor e protagonista).

Por mais que Rousseau se comprometesse no início de suas confissões a relatar os fatos de forma transparente sem jamais recuar, incluindo até aquilo que the fosse desconfortável, o que Coetzee mostra é como essa narrativa crítica de si pode facilmente deslizar para uma narrativa de legitimação ou até mesmo de mitificação do eu. A confissão como método autoinvestigativo permite um trabalho de seleção de conteúdos confessáveis, pois quem confessa algo não deve confessar trivialidades, nem aquilo que é inócuo para a consciência daquele que narra. Quando alguém se confessa, seleciona-se o material doloroso. É desse modo, a partir da seleção do conteúdo, que Coetzee apresenta uma narrativa confessional em seu romance Boyhood.

Em entrevista para David Atwell (1992), Coetzee diz acreditar que a seleção de conteúdo é intrínseca às autonarrativas confessionais. Sobre as autobiografias e a seleção de conteúdo Coetzee afirma que a escrita de si tem a mesma forma de revelar uma verdade que outros gêneros literários. O que a diferencia dos outros gêneros é a sua relação com os fatos históricos de sua própria vida:

I am tempted to try out the following definition on autobiography: that it is a kind of selfwriting in which you are constrained to respect the facts of your history. But which facts? All the facts? No. All the facts are too many facts. You choose the facts insofar as they fall in with your evolving purpose (ATWELL, 1992, p.18). 
Coetzee está considerando aqui a sua preocupação com a verdade e com a narrativa confessional, e não com o processo confessional em si, como ocorre em confissões religiosas. Ele também alerta que a seleção de fatos para a narrativa sobre si mesmo é uma possível explicação do estilo inusitado da narrativa em Boyhood.

Mesmo depois da publicação de seu primeiro romance autobiográfico, Coetzee continuou interessado pelas autonarrativas, como ficou evidente em seu ensaio crítico Phillip Roth, The Plot against America, de 2004. Na obra de Roth, da mesma forma que em Boyhood, há a presença do narrador adulto Phillip Roth em terceira pessoa, apresentando eventos de sua infância. Entretanto, o narrador em Roth é retrospectivo. Sobre esse romance, Coetzee aponta que

The modulation between youthful freshness of vision and adult insight is brought off with such skill that we lose awareness of who is speaking in our ear at any given moment, child or man (...) Subjecting himself to a child's word-view means that Roth has to eschew a range of stylistic resources, in particular the harsher reaches of irony and tirades of desperate eloquence (COETZEE, 2010, p. 240).

No que tange a narrativas confessionais e a autobiografias, Coetzee, portanto, também se mostra um leitor e estudioso assíduo. Seus textos críticos dialogam com seus textos literários e vice-versa.

Diferentemente de As Confissões de Santo Agostinho e das Confissões de Rousseau, Boyhood possui uma qualidade narrativa incomum nas narrativas autobiográficas ou confessionais. Não há no romance, como já dissemos, qualquer ênfase religiosa, calcada na noção de pecado. Além disso, a narrativa não é afetada pela visão do narrador racional refletindo sobre o seu passado, como acontece em Santo Agostinho, em que o sujeito adulto, convertido, pensa e reflete sobre o seu passado de pecados. Como Coetzee evita interferir narrativamente sobre os traços da infância, noções como as de pecado, falta e apreensão precisa da realidade são substituídas pela percepção ingênua e infantil do protagonista; incipiência incorporada na voz narrativa. 
Como a confissão é um método pelo qual é escolhido o material confessado e baseia-se numa verdade sincera que traz à tona aquilo que é doloroso para o sujeito que confessa, é pela seleção de conteúdos que Boyhood se torna um parente moderno das antigas confissões. Mas é preciso lembrar que Coetzee não faz confissão, mas antes usa o apelo subjetivo da confissão no sujeito que confessa para selecionar seu material: a confissão funciona em sua obra como método que define a escolha, e não como gênero ou estilo. Os eventos de vida apresentados na obra, de caráter confessional, se preocupam com a verdade na narrativa, como afirma Attridge (2004, p. 156): "Boyhood enacts the truth of confession, and writing as confession, without transgression, repentance, or absolution".

A relação de Coetzee com a verdade utiliza o conceito de genuíno, no sentido que o pensamento é uma consulta, não de opiniões ou de tendências, mas sim de uma profunda depuração do conhecimento. O apreço de Coetzee pela verdade transparecida na narrativa confessional talvez seja um tema importante no seu ensaio Confessions and Double Thoughts: Rousseau, Tolstoy and Dostoevski (1985). Esse problema é abordado também nas entrevistas para David Atwell, registradas em Doubling the Point (1992). Coetzee, em uma delas, afirma que a verdade "is something that comes in the process of writing, or comes from the process of writing" (ATWELL, 1992, p. 18). Em outras palavras, ele reforça a ideia de que a escrita é um processo complexo de (auto)reflexão através do qual se pode revelar a verdade ou investigar a sua origem.

Embora as narrativas confessionais participem do método coetzeeano, o narrador de Boyhood não se identifica com o sujeito narrado, e, usando sempre a terceira pessoa, evita o movimento repetitivo inercial da retórica confessional e suas segmentações historicamente conhecidas. Attridge (2004) afirma que, em Boyhood, Coetzee cria uma confissão em terceira pessoa, pois estabelece para o autor uma postura de distanciamento enunciativo com o objeto tratado. Esse afastamento permite, por sua vez, evitar as ciladas narcisistas da autodescrição ou da autonarração, ciladas que o próprio Coetzee aponta nas narrativas confessionais de Rousseau e de personagens de Tolstoy e Dostoevski.

Revista Eletrônica Literatura e Autoritarismo: Narrativa Testemunhal e Relações Históricas - ISSN 1679-849X | http://cascavel.ufsm.br/revistas/ojs-2.2.2/index.php/LA/index 
O autor em Boyhood pode ser pensado como religado historicamente ao protagonista, mas não há uma identidade fundindo os dois de modo adamantino. A escolha de escrever sobre si na terceira pessoa não é uma inovação de Coetzee, como pode ser visto nas autobiografias de Henry Adams e Edward Bok, mas, conjugada com a escolha do tempo presente e a seleção de conteúdos como método confessional, constitui uma técnica inovadora em uma narrativa autobiográfica confessional. É possível pensar que Coetzee estivesse ciente de que o uso do narrador em primeira pessoa, ao modo típico de uma narrativa memorialista ou documental, pudesse levar a uma deformação da verdade, ocasionada pela identificação defensiva do autor com o seu protagonista.

A técnica de usar o narrador em terceira pessoa reconfigura a relação entre observador e observado. Ela funciona como um artifício para quebrar mecanismos defensivos da fala do eu. Para analisar o narrador, eis o trecho do fim capítulo de abertura de Boyhood.

The memory of his mother on her bicycle does not leave him. She pedals away up Poplar Avenue, escaping from him, escaping towards her own desire. He does not want her to go. He does not want her to have a desire of her own. He wants her always to be in the house, waiting for him when he comes home. He does not often gang up with his father against her: his whole inclination is to gang up with her against his father. But in this case he belongs with the men (COETZEE, 1997, p. 4).

Devido ao distanciamento ou à outrização do eu (uso da $3^{\text {a }}$ pessoa para falar de si), objeto da narração, o narrador de Boyhood logra se esquivar das racionalizações, avaliações ou julgamentos que faria se tivesse de formular a narrativa em primeira pessoa confessional. Sendo assim, uma das funções realçadas do narrador em terceira pessoa confessional no romance é criar e revigorar a experiência do protagonista infantil, sem submetê-lo ao potencial julgamento a que toda confissão religiosa está sujeita. Portanto, a imagem do sujeito memorialista ou do eu confessante religioso é totalmente opaca em Boyhood. 
O narrador permanece anônimo, não-opinativo, passivo e impassível, ainda que seja o canal através do qual os pensamentos e as sensações do protagonista se manifestam na narrativa:

On the first morning at his new school, while the rest of the class is marched off to assembly in the school hall, he and three other new boys are kept behind. 'What is your religion?' asks the teacher of each of them. He glances right and left. What is the right answer? What religions are there to choose from? Is it like Russians and Americans? His turn comes. 'What is your religion?' asks the teacher. He is sweating, he does not know what to say. 'Are you a Christian or a Roman Catholic or a Jew?' she demands impatiently. 'Roman Catholic' he says (COETZEE, J., 1997, p. 18).

O narrador acessa os pensamentos do protagonista através do discurso indireto livre, como nas perguntas "What is the best answer? What religions are there to choose from?". Porém, o narrador simplesmente apresenta essas perguntas, sem julgá-las ou avaliá-las. Nesse sentido, ao observar a si mesmo exteriormente, fugindo dos sentimentos que envolvem a relação de si consigo mesmo, ocorre o efeito para o leitor como se as impressões e os sentimentos do protagonista emergissem sem interferência de um narrador. $E$ até mais do que isso: sem a intrusão do sujeito adulto. Logo, em Boyhood, características típicas de gêneros autobiográficos como o racionalismo das reconsiderações ex post facto, o memorialismo reconstruído e a condescendência da autorreferência, são diluídas na narrativa confessional.

Mesmo que Coetzee experimente na narrativa de Boyhood elementos e técnicas narrativas que alienam o narrador do personagem da autografia confessional, a seleção de conteúdos do romance conecta-se diretamente com o método confessional. A própria escolha dos eventos de vida (fatos, experiências, observações etc.), tratados sob o ponto de vista do protagonista infantil, não segue uma cronologia, ao modo de uma autobiografia clássica, mas se caracteriza pela intensidade dolorosa dos momentos selecionados. Estes sempre são marcados por situações em que o sujeito vive um momento paradoxal de desconforto perante suas experiências.

Ora, toda confissão, quando realmente dolorosa, pressupõe um conteúdo que provoca inquietação. Portanto, o princípio e o método da 
confissão talvez sejam a base das seleções do modo como as cenas estão dispostas e apresentadas nesse romance. Como exemplos desses episódios, podemos citar quando John convenceu seu irmão a colocar a mão numa máquina de triturar grãos, resultando na amputação do dedo do meio da mão esquerda (COETZEE, 1997, p.129) ou quando John quase morreu afogado em uma atividade com a turma de escoteiros (COETZEE, 1997, p. 16). Se há alguma relação com a confissão no romance de Coetzee, isto acontece a partir da seletividade do conteúdo.

O princípio de confissão evidenciado pela seleção de conteúdo é o fio condutor do livro, pois todos os capítulos tratam de eventos de vida do protagonista permeados (mesmo que de forma indireta) pelos sentimentos de culpa e de vergonha, que estão ligados estritamente à confissão. O excerto a seguir apresenta na narrativa como tais sentimentos são relevantes para o protagonista. A cena passa-se na escola de John, quando seus colegas conversam sobre suas experiências, em particular a punição física que receberam dos professores:

Without experience of his own, he cannot take part in these conversations. Nevertheless, he knows that pain is not the most important consideration. If the other boys can bear the pain, then so can he, whose willpower is so much greater. What he will not be able to endure will be the shame. So bad will be the shame, he fears, so daunting, that he will hold tight to his desk and refuse to come when he is called out. And that will be a greater shame: it will set him apart, and set the other boys against him too. If it ever happens that he is called out to be beaten, there will be so humiliating a scene that he will never again be able to go back to school; in the end there will be no way out but to kill himself (COETZEE, 1997, p. 7).

O sentimento recorrente para John é shame (vergonha). A postura adotada perante esse sentimento é de exagero: o protagonista sente tanta vergonha que tem o desejo de se matar: "in the end there will be no way out but to kill himself'.

É muito provável também que o conceito de confissão na infância seja distorcido e nebuloso, e o uso da linguagem em Boyhood faz com que as experiências apareçam sem a racionalização sobre os atos por um viés ético- 
moral. Essa técnica narrativa permitiria a autopreservação, a denegação do confessante.

A narrativa deste romance desvia, portanto, da retórica tradicional da confissão que não raro aponta um dano moral, um "pecado", uma falha pessoal, mas que ao final, incontestavelmente, foge ao desconforto de sua própria narrativa, produzindo uma justificativa, uma explicação, uma segunda narrativa que moralmente atenua a força da primeira. Por isso, a confissão em Boyhood não é dita nem revelada, mas evidenciada pela seletividade do conteúdo na narrativa. O método confessional na obra opera apresentando os eventos e suspendendo-os em uma aura típica infantil.

\section{Referências}

AGOSTINHO, S. As Confissões. São Paulo: Quadrante, 1985.

ATTRIDGE, D. Coetzee and the Ethics of Reading: Literature in the Event. Chigago: University of Chicago Press, 2004.

, D. Introduction. In: COETZEE, J. M. Inner Workings: Essays 20002005. London: Vintage, 2010, pp ix-xiv.

ATWELL, D. Doubling the point. Essays and Interviews by J. M. Coetzee. Cambridge: Harvard Press University, 1992.

, D. J. M. Coetzee and the Life of Writing. New York: Viking, 2015.

COETZEE, J. M. Boyhood. London: Penguin Group, 1997.

, J. M. Confessions and Double Thoughts: Tolstoy, Rousseau,

Dostoevski. Comparative Literature, v. 37, n. 3, 1985, pp. 193-232.

, J. M. Inner Workings: Essays 2000-2005. London: Vintage, 2010.

, J. M. Summertime. London: Harvill Secker, 2009.

, J. M. Youth. London: Penguin Group, 2003.

EAKIN, P. J. Fictions in Autobiography: Studies in the Art of Self-Invention.

Princeton: Princeton University Press, 2014.

LEJEUNE, P. On Autobiography (Theory and History of Literature). Minnesota: University of Minnesota Press, 1989. 
PEREIRA, L.; ROSENFIELD, K (org.). Lendo J. M. Coetzee. Santa Maria: Editora UFSM, 2015.

ROUSSEAU, J. Confissões. Lisboa. Documentos Humanos, 1964.

SMITH, S.; WATSON, J. Reading Autobiography - A Guide for Interpreting Life Narratives. Minnesota: University of Minnesota, 2010. 